\title{
Association Study for 26 Candidate Loci in Idiopathic Pulmonary Fibrosis Patients from Four European Populations
}

\begin{abstract}
Amit Kishore ${ }^{1}$, Veronika Žižková1, Lenka Kocourková', Jana Petrkova ${ }^{1}$, Evangelos Bouros ${ }^{2}$, Hilario Nunes ${ }^{3}$, Vladimíra Loštáková, Joachim Müller-Quernheim ${ }^{5}$, Gernot Zissel', Vitezslav Kolek ${ }^{4}$, Demosthenes Bouros ${ }^{6}$, Dominique Valeyre ${ }^{3}$ and Martin Petrek ${ }^{1,7 *}$

${ }^{1}$ Laboratory of Immunogenomics, Department of Pathological Physiology, Faculty of Medicine and Dentistry, Palacký University, Olomouc, Czech Republic, ${ }^{2}$ Laboratory of Pharmacology, University Hospital Alexandroupolis, Democritus University of Thrace, Athens, Greece, ${ }^{3}$ Université Paris 13, COMUE Sorbonne Paris Cité, Bobigny, Paris, France, ${ }^{4}$ Department of Respiratory Medicine, Faculty of Medicine and Dentistry, Palacký University, Olomouc, Czech Republic, ${ }^{5}$ Department of Pneumology, Center for Medicine, Medical Center, University of Freiburg, Freiburg, Germany, ${ }^{6}$ Academic Department of Pneumonology, Hospital for Diseases of the Chest 'Sotiria', Medical School, University of Athens, Athens, Greece, ${ }^{7}$ Faculty of Medicine and Dentistry, Institute of Molecular and Translational Medicine, Palacký University and Faculty Hospital, Olomouc, Czech Republic
\end{abstract}

OPEN ACCESS

Edited by:

Pietro Ghezzi,

Brighton and Sussex Medical School,

Reviewed by:

Hideki Ogura,

Yale University, USA

John W. Holloway,

University of Southampton, UK

${ }^{*}$ Correspondence:

Martin Petrek

martin.petrek@fnol.cz

Specialty section: This article was submitted to Inflammation,

a section of the journal

Frontiers in Immunology

Received: 29 January 2016 Accepted: 29 June 2016

Published: 11 July 2016

Citation:

Kishore A, Žižková V, Kocourková L,

Petrkova J, Bouros E, Nunes H, Loštáková V, Müller-Quernheim J,

Zissel G, Kolek V, Bouros D,

Valeyre $D$ and Petrek M (2016) Association Study for 26 Candidate Loci in Idiopathic Pulmonary Fibrosis

Patients from Four European

Populations.

Front. Immunol. 7:274

doi: 10.3389/fimmu.2016.00274
Idiopathic pulmonary fibrosis (IPF) affects lung parenchyma with progressing fibrosis. In this study, we aimed to replicate MUC5B rs35705950 variants and determine new plausible candidate variants for IPF among four different European populations. We genotyped 26 IPF candidate loci in 165 IPF patients from four European countries, such as Czech Republic $(n=41)$, Germany $(n=33)$, Greece $(n=40)$, France $(n=51)$, and performed association study comparing observed variant distribution with that obtained in a genetically similar Czech healthy control population $(n=96)$ described in our earlier data report. A highly significant association for a promoter variant (rs35705950) of mucin encoding MUC5B gene was observed in all IPF populations, individually and combined [odds ratio (95\% confidence interval); $p$-value as 5.23 (8.94-3.06); $1.80 \times 10^{-11}$ ]. Another non-coding variant, rs7934606 in MUC2 was significant among German patients [2.85 (5.05-1.60); $4.03 \times 10^{-4}$ ] and combined European IPF cases [2.18 (3.16-1.50); $3.73 \times 10^{-5}$. The network analysis for these variants indicated gene-gene and genephenotype interactions in IPF and lung biology. With replication of MUC5B rs35705950 previously reported in U.S. populations of European descent and indicating other plausible polymorphic variants relevant for IPF, we provide additional reference information for future extended functional and population studies aimed, ideally with inclusion of clinical parameters, at identification of IPF genetic markers.

Keywords: MUC5B, MUC2, cytokines, idiopathic pulmonary fibrosis, sequenom MassARRAY, single nucleotide polymorphism, association study, network analysis

\section{INTRODUCTION}

Idiopathic pulmonary fibrosis (IPF) is a chronic, progressive form of fibrosing interstitial pneumonia of unknown cause that predominantly affects lung parenchyma, leading to progressive worsening of dyspnea and lung function (1). In pathobiological mechanisms of IPF, role for gene variation has been implicated and spectrum of susceptible/protective polymorphic gene variants, including those 
in loci governing immune and inflammatory reactions and signaling processes, has been recently reported from genome-wide association studies (GWAS) or population-based case-control investigations (2-13); notably distribution of nominated gene variants varied among populations of different ancestry (Table S1 in Supplementary Material). Further, recent bioinformatics approaches yielded a genomic model that accurately predicted high- and low-risk IPF patients using a list of 118 IPF prognostic predictor genes, many of those with immune-, also T-cell-related functions (14). In aggregate, these reports implicated involvement of multiple genetic factors in IPF development and emphasized the need for their evaluation in different populations to decipher the plausible pathobiological mechanism of IPF.

In context of the above efforts, we have recently identified and reported 26 IPF-associated candidate loci (15). Besides characterizing their major functions, e.g., in regulating production of mucins (MUC5B and MUC2) or of pro-inflammatory cytokines (IL-1, IL-8) and also in cell signaling and innate immunity processes (TLR3 and TOLLIP) involved in inflammatory and profibrotic pathways (http://www.ncbi.nlm.nih.gov/pmc/articles/ PMC4585032/table/T1/), we have described the approach for their simultaneous investigation using a novel mass spectrometry based matrix-assisted laser desorption/ionization time-of-flight (MALDI-TOF) multiplexed genotyping assay and reported their gene frequencies in healthy Czech (European) population (15). There, we also suggested the wider application of the data from this report for association studies among genetically homogenous populations following the recommendation of STrengthening the REporting of Genetic Association studies (STREGA) (16). Suggestion to include this particular control population in the present IPF association study in different European populations was based on reports of genetic similarity among Europeans, for example from results of genotyping 6000 individuals as control samples for $>300,000$ single nucleotide polymorphisms (SNPs) in a GWAS (17) and findings of a HapMap study (18). Further, in our decision we also reflected recommendations of HLA-NET network group for usage of geographical and/or cultural criteria to describe human populations (19) and also our own observations of substantial degree of homogeneity in distribution of immune-related gene variants within European populations, including Greeks (20).

Hereby, we report the results from a multicenter association gene study in which we determined the status (genotype distribution, genotype, and allele frequencies with carriage rate) of 26 IPF candidate loci. Here, we have performed a comparative study for association of these IPF candidate genetic variants among four different European (Czech, German, Greek, and French) populations and have ammended it by network prediction for gene-gene/gene-phenotype interactions in IPF and lung biology. We suggest that future extended and replicative studies following hereby described approach could enable better understanding of IPF pathogenesis, and if further supported by patient laboratory and clinical data, it could help to nominate novel disease markers.

\section{MATERIALS AND METHODS}

\section{Characteristics of IPF Cases}

In this study, 165 IPF patients from four European populations comprising 41 Czechs (Centre: University Hospital, Olomouc), 33 Germans (University Medical Center, Freiburg), 40 Greeks (Medical School University, Athens), and 51 French (University Hospital, Paris), representing Central, Southern, and Western Europe, were enrolled (Table 1).

All subjects were unrelated, white, and of European origin living in specified countries of Europe and speaking their respective national languages. The IPF cases were diagnosed as per ATS/ERS/JRS/ALAT guidelines $(1,21,22)$ with typical clinical features and abnormalities on chest high-resolution computed tomography (HRCT) scans, abnormal lung function tests with reduced diffusing capacity of the lung for $\mathrm{CO}\left(\mathrm{DL}_{\mathrm{CO}}\right)$, and/or restrictive pulmonary deficit, exclusion of other known causes of interstitial lung disease (ILD). For comparisons of genotype, allele frequency, and carriage rate (phenotype frequency) of analyzed genomic variants and case-control association study, we have utilized the data on distribution of these variants in 96 Czech healthy controls (15). Genomic DNA was isolated from peripheral blood leukocytes by standard salting out method (23). Informed consent was obtained from all study participants. The study was performed with approval of institutional ethical committees at respective centers (Ethics Commitee of University Hospital and Medical Faculty of Palacky University, Olomouc, Czech Republic; Ethics Committee of the University Hospital Freiburg, Germany; Ethics Committee Hospital for Diseases of the Chest, Athens, Greece; and Comité Consultatif de protection des Personnes dans la recherche biomédicale-hôpital Robert Ballanger, France).

\section{Assay Design, PCR Amplification and Genotyping}

The details of the panel comprising 26 IPF candidate loci and genotyping procedure in IPF cases have been described

TABLE 1 | Subjects characteristics under study comprising IPF cases from four different populations.

\begin{tabular}{|c|c|c|c|c|c|c|}
\hline & Control subjects ${ }^{a}$ & \multicolumn{5}{|c|}{ European IPF cases } \\
\hline$N$ & 96 & 41 & 33 & 40 & 51 & 165 \\
\hline Age, range & $18-57$ & $42-81$ & $36-85$ & 51-88 & 36-92 & 36-92 \\
\hline Males:females & $45: 51$ & $23: 18$ & $26: 7$ & $32: 8$ & $44: 7$ & $125: 40$ \\
\hline
\end{tabular}

aHealthy control subjects from our previous data report (15). 
previously (15). In brief, a total of 26 SNPs reported as associated with IPF in literature were selected. These SNPs were located within the genes of different functional categories (mucus production, pro-inflammatory cytokines, chemokines, innate immune response, telomerase maintenance, cell surface remodeling, GTPase activator activity, cell-cycle regulators, phospholipid translocators, desmoplakin production, etc.). For PCR amplification and single base extension (SBE) reaction, the primer pairs along with extension primers were designed using Assay design suite v2.0. These primers were multiplexed and genotyped using Sequenom MassARRAY platform integrating iPLEX $^{\circledR}$ SBE reaction and MassARRAY ${ }^{\circledR}$ technology (Agena Bioscience, San Diego, CA, USA) based MALDI-TOF MS assay. The assay consists of an initial locus-specific PCR amplification followed by SBE using mass-modified dideoxynucleotide terminators of an oligonucleotide primer that anneals immediately upstream of the target polymorphic site. The distinct mass of extended primer traces the alternative alleles using MassARRAY Typer 4.0.20. For quality control (QC) step, we determined data missing rate per individuals and missing rate per SNP. Also, for QC of SNP genotyping, positive and negative template control samples were included in each assay plate. Any assay found as positive in negative template control were removed from the study.

\section{Statistical Analysis}

Each SNP was tested for Hardy-Weinberg equilibrium (HWE) by Pearson's Chi-square $\left(\chi^{2}\right)$ test or Fisher exact test, as applicable. SNPs within HWE $(p>0.05)$ and sufficiently common [minor allelefrequency $(\mathrm{MAF})>5 \%$ ] in studied population were included. Carriage rate (phenotype frequency) was calculated as number of individuals carrying one (or two) copies of a particular allele on one or both (maternal and paternal) chromosomes. Association of SNPs minor alleles with IPF susceptibility were evaluated by Fisher's exact test providing odds ratio (OR), 95\% confidence interval $(\mathrm{CI})$, and level of significance $(p)$. For Bonferroni correction of multiple comparison (number of test $=100$; 20 SNPs for four individual and the combined populations), a stringent approach with $p$-value $<0.05 / 100\left(5 \times 10^{-4}\right)$ was considered as significant.

\section{Network Analysis}

Prediction of gene-gene network for plausible candidate variants $(p<0.05)$ and their interaction with IPF and other phenotypes, such as lung disease, lung injury, and lung function was performed using Phenolyzer, a tool for phenotype-based prioritization of candidate genes in human diseases (24). The candidate genes and their relationship with IPF and related phenotypes were investigated in several databases to determine and score relevant seed genes. The seed genes are then expanded to include related genes, on the basis of several types of gene-gene relationship components, such as exhibiting a protein-protein interaction, sharing a gene family or biological pathway, or transcriptionally regulating or being regulated by another gene. Finally, these different types of scores from seed gene ranking and gene-gene relationships are integrated to generate a ranked candidate gene list, together with gene-gene and gene-phenotypes interactions used to normalize the scores in range $0-1$ (24).

\section{RESULTS}

The characteristics of IPF patients and healthy control subjects included in this study are presented in Table $\mathbf{1}$. The proportions of IPF male cases were higher than of female cases. Following QC steps for missing rates, the genotyping data from all individual passed the QC with (i) missing frequency per individual 0.038 $\left(\mathrm{N} \_M I S S=1\right)$ to 0.077 (N_MISS = 2) (a single IPF case from Greek population that failed the assay was not included in this study), and (ii) genotype missing frequency (F_MISS/assay error rate; Table 2) 0.004 to 0.015 . Five SNPs showed departure from HWE (Table S2 in Supplementary Material), namely, PRKCE rs628877 $(p=0.02$ in combined IPF cases with F_MISS $=0.008)$, $I L-4$ rs2243250 ( $p=0.01$, F_MISS $=0.0146$ in Czech IPF and $p=1.2 \times 10^{-4}, \mathrm{~F} \_$MISS $=0.011$ in combined IPF cases), $I L-4$ rs2070874 ( $p=0.02, \mathrm{~F} \_$MISS $=0$ in Czech IPF), IL-4R $\alpha$ rs 1801275 $(p=0.04$, F_MISS $=0$ in Czech healthy controls; $p=0.03$, F_MISS $=0$ in Greek IPF and $p=0.01$, F_MISS $=0$ in combined IPF cases), and MAPT rs1981997 ( $p=0.03, \mathrm{~F} \_$MISS $=0.007$ in French IPF cases). Further, with MAF threshold check, TP53 rs12951053 was found with MAF $=0.04$, F_MISS $=0$ in Greek IPF cases. Thus, keeping the QC stringent conditions, these six SNPs were removed from further analysis, for which 20 variants remained (Table 2).

The primary analysis $(p<0.05)$ using allelic (multiplicative) genetic model revealed a total of nine SNPs for IPF susceptibility. Among these, three SNPs were shared among different IPF populations: first, rs35705950^T within promoter region of $M u c i n 5 B$ (MUC5B) was highly significant among all the IPF populations - Czech [OR (95\% CI); p: 3.77 (7.47-1.9); $1.62 \times 10^{-4}$ ]; German [4.83 (9.79-2.39); $\left.1.55 \times 10^{-5}\right]$; Greek [5.46 (10.82-2.76); $\left.1.13 \times 10^{-6}\right]$; French [6.77 (12.65-3.62); $\left.5.28 \times 10^{-10}\right]$; and combined IPF cases $\left[5.23(8.94-3.06) ; 1.80 \times 10^{-11}\right]$ (Table 2). Second, rs7934606*A within intron region of Mucin2 (MUC2) was significant for German [2.85 (5.05-1.60); $\left.4.03 \times 10^{-4}\right]$, Greek [2.45 (4.19-1.43); $\left.1.43 \times 10^{-3}\right]$, French $\left[2.36(3.86-1.44) ; 7.03 \times 10^{-4}\right]$, and combined IPF $\left[2.18(3.16-1.50) ; 3.73 \times 10^{-5}\right]$ cases. The third variant, rs $1799899^{*} \mathrm{~A}$ located in exon region of Transferrin $(T F)$ gene was significant for Germans [2.89 (6.47-1.30); $\left.1.12 \times 10^{-2}\right]$, French $\left[2.20(4.65-1.04) ; 4.58 \times 10^{-2}\right]$, and in combined IPF [2.06 (3.78-1.12); $1.87 \times 10^{-2}$ ] cases. Prediction of loss-/gain-offunction for functional variant TF rs1799899 suggested it as a probably damaging mutation (Polyphen score: 0.869 and SIFT score: 0.07 ).

The other six significant SNPs were featured in individual populations of which three were associated with IPF in Czech: (i) $\mathrm{rs} 12602273^{\star} \mathrm{G}$ in Tumor protein 53 (TP53) [2.43 (5.3-1.11); $\left.3.10 \times 10^{-2}\right]$; (ii) $\mathrm{rs} 4277405^{\star} \mathrm{C}$ in Angiotensin converting enzyme

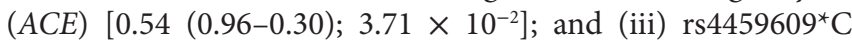
in ACE $\left[0.54(0.96-0.30) ; 3.71 \times 10^{-2}\right]$ and one each in Greek:

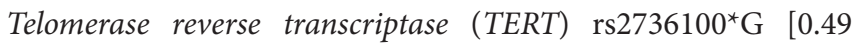
(0.83-0.29); $\left.1.12 \times 10^{-2}\right]$; French: ATPase, type $11 A($ ATP11A) rs $1278769^{*} \mathrm{~A}\left[0.51(0.92-0.28) ; 2.51 \times 10^{-2}\right]$; and in total IPF cases: Interleukin-1 $\alpha(I L-1 \alpha)$ rs1800587 ${ }^{\star}$ [0.68 (0.99-0.46); $4.94 \times 10^{-2}$ ] (Table 2).

These findings of allelic model were in concordance with Pearson's $\chi^{2}$ test and additive test of logistic regression analysis 
TABLE 2 | Allelic model of association for IPF risk among four European populations.

\begin{tabular}{|c|c|c|c|c|c|c|c|c|c|}
\hline \multirow{2}{*}{$\begin{array}{l}\text { S. } \\
\text { No. }\end{array}$} & \multirow[t]{2}{*}{ Gene } & \multirow[t]{2}{*}{ SNP } & \multirow{2}{*}{$\begin{array}{l}\text { Minor } \\
\text { allele }\end{array}$} & Czechs & Germans & Greeks & French & Total & \multirow{2}{*}{$\begin{array}{l}\text { Assay error } \\
\text { rate }\end{array}$} \\
\hline & & & & OR $(95 \% \mathrm{Cl}) p$ & OR $(95 \% \mathrm{Cl}) p$ & OR $(95 \% \mathrm{Cl}) p$ & OR $(95 \% \mathrm{Cl}) p$ & OR $(95 \% \mathrm{Cl}) p$ & \\
\hline 1 & $I L-1 \alpha$ & rs1800587 & T & $0.65(1.16-0.37) 0.16$ & $0.78(1.42-0.42) 0.45$ & $0.56(1.01-0.31) 0.06$ & $0.74(1.25-0.44) 0.30$ & $0.68(0.99-0.46) 4.94 \times 10^{-2}$ & 0 \\
\hline 2 & $L-1 \beta$ & rs16944 & A & $1.15(1.98-0.67) 0.67$ & $0.79(1.46-0.42) 0.54$ & $1.01(1.76-0.58) 1.00$ & $1.14(1.9-0.69) 0.61$ & $1.03(1.51-0.71) 0.92$ & 0 \\
\hline 3 & $I L-1 \beta$ & rs1143634 & T & $1.06(1.93-0.59) 0.88$ & $1.34(2.49-0.72) 0.42$ & $0.71(1.37-0.37) 0.34$ & $1.06(1.84-0.61) 0.89$ & $1.02(1.54-0.68) 1.00$ & 0 \\
\hline 4 & LRRC34 & rs6793295 & C & $0.87(1.55-0.49) 0.66$ & $0.96(1.77-0.52) 1.00$ & $0.79(1.43-0.44) 0.46$ & $1.35(2.24-0.81) 0.29$ & $1.00(1.48-0.68) 1.00$ & 0 \\
\hline 5 & TF & rs1799899 & A & $1.46(3.47-0.61) 0.48$ & $2.89(6.47-1.3) 1.12 \times 10^{-2}$ & $1.88(4.3-0.82) 0.17$ & $2.20(4.65-1.04) 4.58 \times 10^{-2}$ & $2.06(3.78-1.12) 1.87 \times 10^{-2}$ & 0 \\
\hline 6 & IL-8 & rs4073 & A & $1.28(2.14-0.76) 0.36$ & $1.16(2.03-0.66) 0.67$ & $1.16(1.95-0.69) 0.60$ & $1.11(1.8-0.69) 0.71$ & $1.17(1.67-0.82) 0.41$ & 0 \\
\hline 7 & FAM13A & rs2609255 & G & $1.01(1.82-0.56) 1.00$ & $0.79(1.54-0.4) 0.51$ & $1.04(1.88-0.57) 0.88$ & $1.46(2.47-0.86) 0.17$ & 1.09 (1.64-0.73) 0.68 & 0 \\
\hline 8 & TLR3 & rs3775291 & A & $0.94(1.62-0.54) 0.89$ & $0.61(1.16-0.32) 0.17$ & $0.72(1.29-0.41) 0.32$ & $0.72(1.22-0.43) 0.24$ & $0.75(1.1-0.51) 0.14$ & 0 \\
\hline 9 & TERT & rs2736100 & G & $1.01(1.70-0.60) 1.00$ & $0.85(1.51-0.48) 0.67$ & $0.49(0.83-0.29) 1.12 \times 10^{-2}$ & $1.23(1.99-0.76) 0.46$ & $1.23(1.76-0.86) 0.28$ & 0 \\
\hline 10 & IL-13 & rs1800925 & T & $0.66(1.22-0.35) 0.23$ & $0.65(1.27-0.34) 0.26$ & $1.08(1.91-0.61) 0.88$ & $0.83(1.43-0.48) 0.59$ & $0.80(1.2-0.54) 0.30$ & 0.008 \\
\hline 11 & IL-4 & rs2243248 & G & $0.47(1.69-0.13) 0.29$ & $0.59(2.13-0.16) 0.57$ & $1.78(4.19-0.75) 0.24$ & $1.20(2.88-0.5) 0.66$ & $1.02(2.01-0.52) 1.00$ & 0.008 \\
\hline 12 & CDNK1A & rs733590 & C & $1.21(2.05-0.72) 0.50$ & $0.76(1.38-0.42) 0.46$ & $1.15(1.95-0.67) 0.68$ & $1.01(1.65-0.62) 1.00$ & $1.03(1.49-0.72) 0.93$ & 0 \\
\hline 13 & OBFC1 & rs11191865 & A & $1.67(2.81-0.99) 0.06$ & $1.75(3.07-0.99) 0.06$ & $1.07(1.8-0.63) 0.89$ & $1.43(2.31-0.88) 0.18$ & $1.44(2.06-1.01) 0.06$ & 0 \\
\hline 14 & MUC2 & rs7934606 & A & $1.41(2.41-0.83) 0.21$ & $2.85(5.05-1.60) 4.03 \times 10^{-4}$ & $2.45(4.19-1.43) 1.43 \times 10^{-3}$ & $2.36(3.86-1.44) 7.03 \times 10^{-4}$ & $2.18(3.16-1.50) 3.73 \times 10^{-5}$ & 0.004 \\
\hline 15 & MUC5B & rs35705950 & T & $3.77(7.47-1.9) 1.62 \times 10^{-4}$ & $4.83(9.79-2.39) 1.55 \times 10^{-5}$ & $5.46(10.82-2.76) 1.13 \times 10^{-6}$ & $6.77(12.65-3.62) 5.28 \times 10^{-10}$ & $5.23(8.94-3.06) 1.80 \times 10^{-11}$ & 0.015 \\
\hline 16 & ATP11A & rs1278769 & A & $1.10(1.92-0.63) 0.77$ & $0.53(1.06-0.26) 0.08$ & $1.02(1.79-0.57) 1.00$ & $0.51(0.92-0.28) 2.51 \times 10^{-2}$ & $0.76(1.13-0.51) 0.18$ & 0 \\
\hline 17 & TP53 & rs12602273 & G & $2.43(5.3-1.11) 3.10 \times 10^{-2}$ & $1.40(3.6-0.54) 0.45$ & $1.13(2.89-0.44) 0.81$ & $1.57(3.5-0.71) 0.29$ & $1.63(3.03-0.87) 0.14$ & 0 \\
\hline 18 & $A C E$ & rs4277405 & C & $0.54(0.96-0.30) 3.71 \times 10^{-2}$ & $1.08(1.92-0.61) 0.88$ & $1.11(1.9-0.65) 0.78$ & $1.12(1.83-0.68) 0.71$ & $0.94(1.36-0.65) 0.78$ & 0 \\
\hline 19 & $A C E$ & rs4459609 & C & $0.54(0.96-0.30) 3.71 \times 10^{-2}$ & $1.08(1.92-0.61) 0.88$ & $1.11(1.9-0.65) 0.78$ & $1.08(1.76-0.66) 0.80$ & $0.93(1.34-0.64) 0.71$ & 0 \\
\hline 20 & DPP9 & rs12610495 & G & $1.01(1.82-0.56) 1.00$ & $1.56(2.85-0.86) 0.15$ & $1.01(1.84-0.55) 1.00$ & $1.14(1.96-0.66) 0.68$ & $1.15(1.72-0.77) 0.54$ & 0.008 \\
\hline
\end{tabular}

Bold values are significant with Bonferroni corrected $p<5 \times 10^{-4}$.

OR: Odds ratio; Cl: Confidence interval. 


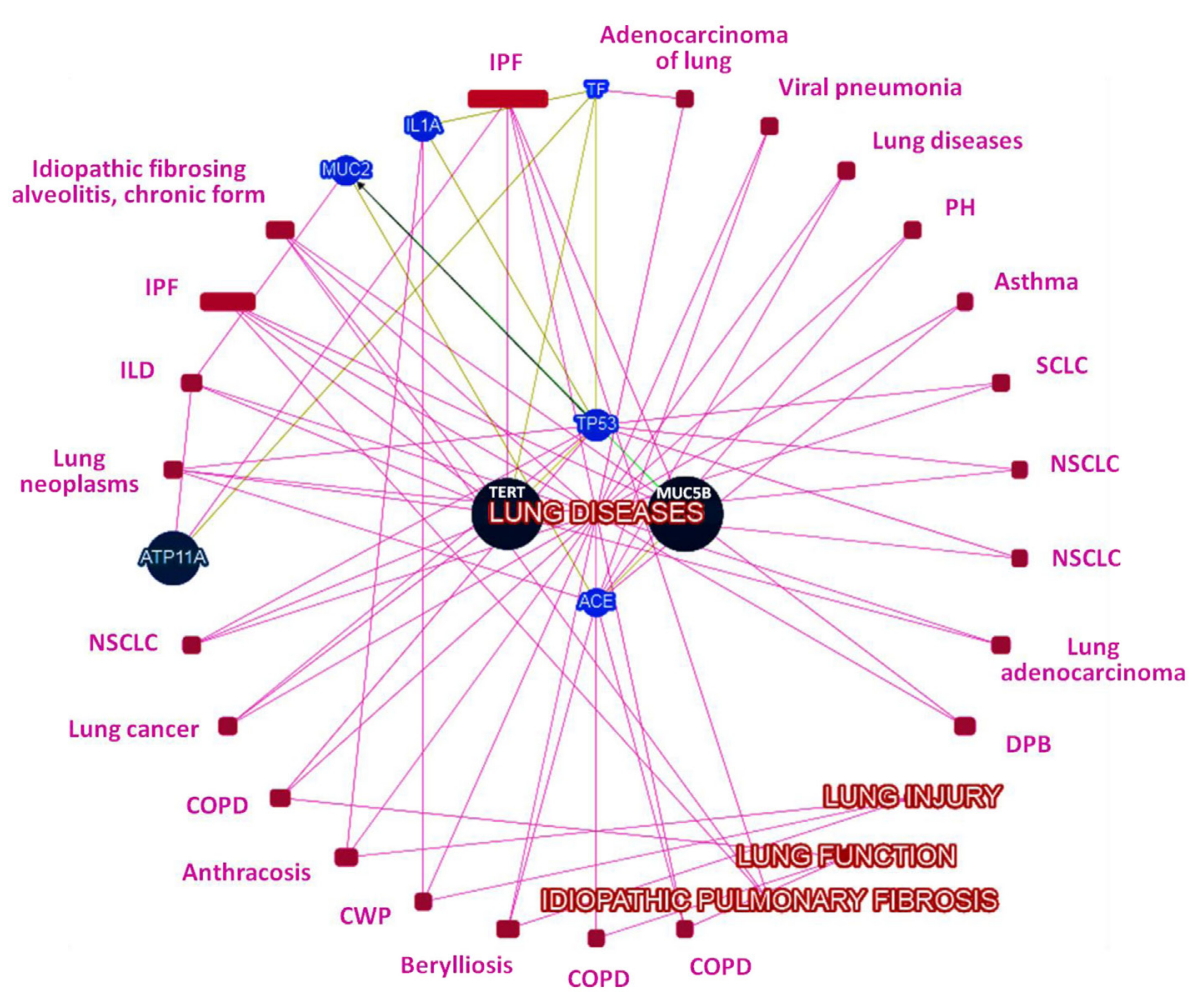

FIGURE 1 | Network of genes with candidate loci and their interaction with IPF, lung injury, lung function, and lung disease phenotypes (ILD, interstitial lung disease; CWP, coal worker's pneumoconiosis; COPD, chronic obstructive pulmonary disease; DPB, diffuse panbronchiolitis; NSCLC, non-small cell lung cancer; SCLC, small cell lung cancer; $\mathrm{PH}$, pulmonary hypertension).

with similar panel and population distribution/stratification of significant risk variants, and an exceptional addition of rs $11191865^{\star} \mathrm{A}(p=0.046)$ in Oligonucleotide/oligosaccharidebinding fold containing 1 (OBFC1) exclusively in total IPF set under $\chi^{2}$ test.

Network analysis among genes with significant variants showed MUC5B and MUC2 in same gene family (Figure S1 in Supplementary Material), transcriptional interaction among MUC2 and TP53 (Figure S2 in Supplementary Material), and all identified candidate genes belonged to the same biosystem (Figure S3 in Supplementary Material). Further prediction based on their records in several databases (CLINVAR, ORPHANET, OMIM, DISGENET, GWAS, HTRI, GENE_FAMILY, and BIOSYSTEM), gene-gene interaction and interaction with phenotypes (IPF, lung disease, lung injury, and lung function) has (Figure 1) prioritized $M U C 5 B$ as highest-ranked genes and indicated MUC5B, TERT, and ATP11 $a$ as seed genes, while TP53, IL1A, MUC2, ACE, and TF as predictive genes based on their normalized scores (Figure 2).

Applying rather conservative Bonferroni correction for multiple comparisons (100 tests, see Materials and Methods), MUC5B rs35705950*T remained as highly significant in all IPF populations, Czech $\left(p=1.62 \times 10^{-4}\right)$, German $\left(1.55 \times 10^{-5}\right)$, Greek $\left(1.13 \times 10^{-6}\right)$, French $\left(5.28 \times 10^{-10}\right)$, and in combined IPF population $\left(1.80 \times 10^{-11}\right)$; whereas MUC2 $\mathrm{rs} 7934606^{*} \mathrm{~A}$ was significant in German $\left(4.03 \times 10^{-4}\right)$ and in combined IPF $\left(3.73 \times 10^{-5}\right)($ Table 2$)$. The inheritance hypothesis for Bonferroni significant variants, MUC5B rs35705950 and MUC2 rs7934606, under allelic model for IPF association were also tested for other models and the variant rs35705950 was found in concordance to the dominant model indicating allele $\mathrm{T}$ for increased risk (Table 3).

For the highly significant variants, we also report the allele frequency of rs35705950*T risk allele to range from 0.09 to 0.41 and rs7934606*A from 0.32 to 0.58 among the analyzed four European populations (Table S2 in Supplementary Material). Among IPF cases, the allele frequency and carriage rate for $\mathrm{rs} 35705950{ }^{\star} \mathrm{T}$ were lowest in Czech (0.28 and 0.49, respectively) and highest in French ( 0.41 and 0.65 , respectively); while $\mathrm{rs} 7934606^{\star} \mathrm{A}$ has lowest frequencies in Czech ( 0.40 and 0.63 , respectively) and highest in Germans (0.58 and 0.91, respectively).

\section{DISCUSSION}

This study is a first report of comparative distribution of genotypes and alleles of 26 candidate gene variants implicated in mucin production, cell-cycle regulation, pro-inflammatory, and profibrotic signaling pathways pertinent to IPF pathobiology among patients from four populations across Europe (Czech, German, Greek, and French). Employing stringent statistical approach $\left(p<5 \times 10^{-4}\right)$, we report a high association between MUC5B rs35705950*T and IPF susceptibility in all the four analyzed populations among Czechs: [OR (95\% CI) p] 3.77 (7.47-1.9) 


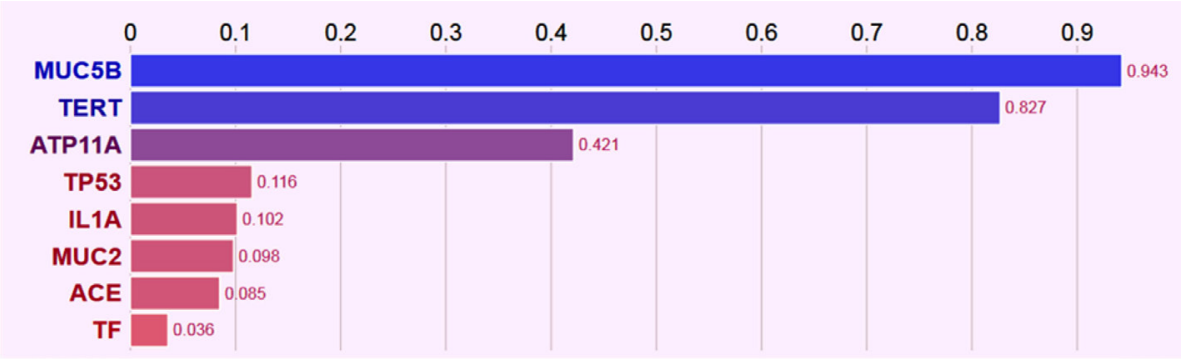

FIGURE 2 | Bar plot of seed genes (MUC5B, TERT, and ATP11a) and predicted genes (TP53, IL1A, MUC2, ACE, and TF) normalized scores based on the gene-gene and gene-phenotype interactions

TABLE 3 | Dominant model of inheritance for highly significant IPF susceptible risk variants with Bonferroni correction among the four European populations.

\begin{tabular}{|c|c|c|c|c|c|}
\hline \multirow[t]{2}{*}{ Genetic variants } & Czech & German & Greek & French & Total IPF \\
\hline & OR $(95 \% \mathrm{Cl}) ; p$ & OR (95\% Cl); p & OR $(95 \% \mathrm{Cl}) ; p$ & OR (95\% Cl); p & OR $(95 \% \mathrm{Cl}) ; \boldsymbol{p}$ \\
\hline $\begin{array}{l}\text { MUC5B rs35705950*T } \\
\text { (GT + TT vs. GG) }\end{array}$ & $\begin{array}{c}4.76(2.11-10.75) \\
2.21 \times 10^{-4}\end{array}$ & $\begin{array}{c}8.75(3.59-21.30) \\
9.04 \times 10^{-7}\end{array}$ & $\begin{array}{c}6.25(2.67-14.60) \\
1.97 \times 10^{-5}\end{array}$ & $\begin{array}{c}9.167(4.18-20.12) \\
9.6 \times 10^{-9}\end{array}$ & $\begin{array}{c}7.01(3.77-13.06) \\
6.21 \times 10^{-11}\end{array}$ \\
\hline $\begin{array}{l}\text { MUC2 rs7934606*A } \\
(\mathrm{GA}+\mathrm{AA} \text { vs. GG) }\end{array}$ & 1.29 (0.61-2.74); NS & $\begin{array}{c}7.45(2.13-26.12) \\
2.73 \times 10^{-4}\end{array}$ & $\begin{array}{c}2.48(1.06-5.80) \\
4.83 \times 10^{-2}\end{array}$ & $\begin{array}{c}2.71(1.24-5.92) \\
1.16 \times 10^{-2}\end{array}$ & $\begin{array}{c}2.47(1.43-4.26) \\
1.27 \times 10^{-3}\end{array}$ \\
\hline
\end{tabular}

Bold values are significant with Bonferroni corrected $p<5 \times 10^{-4}$

OR, Odds ratio; $\mathrm{Cl}$, Confidence interval; NS, Non-significant.

$1.62 \times 10^{-4}$, Germans: $4.83(9.79-2.39) 1.55 \times 10^{-5}$, Greeks: $5.46(10.82-2.76) 1.13 \times 10^{-6}$, and French: 6.77 (12.65-3.62) $5.28 \times 10^{-10}$ along with all patients from this study as a whole: 5.23 (8.94-3.06) $1.80 \times 10^{-11}$. Thus, we replicate previous findings and provide an insight for predominant association of gelforming mucin-encoding gene variants with IPF in Europeans and populations of European descent. The role of mucin variants was also supported with high significance of MUC2 rs7934606 among Germans [2.85 (5.05-1.60); $4.03 \times 10^{-4}$ ] and combined European IPF cases $\left[2.18(3.16-1.50) ; 3.73 \times 10^{-5}\right]$. The identified nine variants among $M U C 5 B, M U C 2, T F, T P 53, A C E, T E R T$, $A T P 11 A$, and $I L-1 \alpha$ (significant at $p<0.05$ ) were interactive at gene-gene and gene-phenotype level in network analysis. The present study for inter-population comparison is imperative with respect of comparing the distributions of plausible IPF-associated gene variants and, thus, may provide starting point(s) for further investigations of biological (functional implication of nominated loci) and translational (relationship with laboratory/clinical parameters) aspects.

Among mucin gene cluster (MUC6, MUC2, MUC5AC, and $M U C 5 B)$ on chromosome $11 \mathrm{q} 15.5, M U C 5 B$ is the most predominant in the normal distal airway epithelium and is widely associated with sporadic IPF and familial interstitial pneumonia (9, 25-27). The MUC5B promoter-variant rs35705950 SNP predicted change in transcription factors binding sites (disruption of E2F and creation of HOX9 and PAX2) and the risk T-allele has been strongly associated with increased MUC5B expression in the lung tissue. The relative high frequency of rs35705950*T risk allele (IPF cases: $0.28-0.41$ and healthy controls: 0.09 ) observed in this study are in concordance with several reports, including populations of European descent (Table S1 in Supplementary Material). To explain the mucin-expressing structures in IPF pathogenesis, Seibold et al. analyzed ciliated, basal, and alveolar type II cells in lung tissue and reported predominant expression of $M U C 5 B$ in pseudostratified mucociliary epithelium comprised of basal epithelial cells and mucus cells in distal airway. Further, it is suggested that mucociliary dysfunction in the distal airway causing honeycomb cyst may play a role in the development of progressive fibroproliferative lung disease $(25,27)$. Although rs35705950 is reported as highly associated with IPF in Europeans and in populations of European descent, interestingly, it is weakly associated in East-Asians, such as Chinese, Japanese, and Koreans (Table S1 in Supplementary Material). Another mutation in the same gene family (Figure S1 in Supplementary Material) identified MUC2 rs79834606 as significantly associated in IPF $\left(p=3.8 \times 10^{-6}\right)$ with MAF (A-allele) 0.54 in IPF cases and 0.41 in controls (9), which is in accordance to our present findings (IPF: $0.40-0.58$ and controls: 0.32) (Table S2 in Supplementary Material). Similarly, MAF of 0.52 for $r s 79834606^{\star} A$ was reported among IPF cases in a GWAS (3).

Here, we newly identified rs1799899 located in the TF gene as IPF risk variant in Germans, French, and in combined European IPF cases, significant at primary analysis $\left(0.05>p>5 \times 10^{-4}\right)$. The SNP rs1799899 marks a Gly/Ser change located in TF gene encoding a glycoprotein involved in iron ion transport and removal of certain organic matter and allergens from serum. As this is the first implication of TF gene in context of IPF, in parallel to the studies of its possible functional role, this association requires 
replication (16). The other six IPF risk variants identified in this study were featured among individual populations (Table 2). Among Czech IPF cases, (i) SNP rs12602273 located in intron of TP53 that regulates cell-cycle arrest; while, (ii) rs4277405 and (iii) rs4459609 located in promoter region of ACE-II suggested with critical profibrotic role in IPF $(28,29)$ were observed. The MAF of $\mathrm{rs} 12602273^{\star} \mathrm{G}$ reported as 0.07 in IPF case and 0.08 in healthy population of the Netherlands (11) was comparable to our current findings (IPF: 0.09-0.12 and controls: 0.08). For Greek IPF cases, (iv) a common variant rs 2736100 within intron of TERT and (v) rs1278769 in 3'-UTR of ATP11A were significant. Several studies have reported the telomerase gene mutation causing short telomerase as risk factor and poor survival in $\operatorname{IPF}(2,30$, 31). These variants, $r s 2736100^{\star} \mathrm{G}$ and $\mathrm{rs} 1278769^{*} \mathrm{~A}$, were initially reported in a GWAS study for IPF cases with MAF of 0.43 and 0.20 , respectively (MAF $=0.41-0.63$ and $0.18-0.30$, respectively in this study) (3). Besides, (vi) rs1800587 in 5'-flanking region of pro-inflammatory cytokine $I L-1 \alpha$ was lesser significant among the combined IPF cases. Earlier, a study in Czech population has reported rs $1800587^{\star} \mathrm{T}$ MAF of 0.30 in IPF cases and 0.32 in healthy controls (4), similar to our current finding (IPF: 0.27-0.29 and controls: 0.36$)$.

While MUC5B rs35705950 is highly replicable, the other probable candidate variants (including new report of $T F$ rs1799899 in IPF) reported in this study must be replicated in accordance to the guidelines for conductance of genetic association studies (16), by other independent studies. However, already at this stage, our analysis of the gene-gene and gene-phenotype interaction networks suggests that these candidate variant genes are pertinent to IPF and lung function biology (Figure 1) and provides support for biological plausibility of observed variants.

Apart from using Czech population control data for comparisons within the European context, which was noted and reasoned for in the Section "Introduction," another limitation of this study is that a single national center was included for each of four European populations, where a relatively small number of IPF cases were genotyped, which reduces the power of our present findings. However, with a conservative incidence range of 3-9 cases per 100,000 per year for Europe (32), the enrolled sample size (165 IPF cases) in the present study considerably represents the disease among Europeans; moreover, it is comparable with sizes of other reported studies (Table S1 in Supplementary Material). Off note, our primary aim was to report our findings of the candidate IPF genetic variants so that these could be replicated in other centers (16) and investigated further. In this regard, investigations of relationships with clinical parameters such as lung functions will follow.

Our findings provide evidence that gene variants involved in mucin production (MUC5B and MUC2) do increase IPF risk among the four European populations, two of which (Czech and Greek) have not been studied before in this regard at all. Additionally, the nominated variants in $T F$ and other variants of TP53, ACE, TERT, ATP11A, and IL-1 $\alpha$ may also contribute to IPF susceptibility. Despite our panel of 26 gene variants was designed across pertinent pathobiological pathways, it did not include others from the wide range of plausible IPF-associated
SNPs regulating immune and fibrotic functions, such as master regulator TGF- $\beta$, TNF- $\alpha$, full spectrum of TLRs, MHC (HLA) variants, and also SNPs in regulatory microRNAs (miRNAs) (4, $8,33,34)$. Therefore, these variants should be prioritized in the future studies aimed at extending a profile general and population-specific IPF gene biomarkers, including exploration of their functions, so that our view on the role of gene variation in origin of IPF and its further development more closely approaches the reality.

\section{CONCLUSION}

The present study confirms and further extends strong association of MUC5B promoter region variant (rs35705950) with IPF disease among Europeans. In addition, it suggests further IPF-associated polymorphisms: MUC2 (rs79834606) and TF (rs1799899) variants in general, and the other six (TP53 rs12602273, ACE-II rs4277405, ACE-II rs4459609, TERT rs2736100, ATP11A rs1278769, and IL$1 \alpha$ rs1800587) in individual European populations. Their further investigation for disease association among extended patient cohorts is, therefore, warranted. At the same time, findings of our present study represent reference information to be utilized for future extended functional and population studies as well as for translational research of the nominated variants aiming at characterization of biomarkers and/or novel therapeutic targets.

\section{ETHICS STATEMENT}

The study was approved by the ethical committee of the University Hospital, Olomouc; University Medical Center, Freiburg; Medical School University, Athens; and University Hospital, Paris. After approval of the study by ethical committee, the consent of human participants visiting the centres was taken in written for usage of biological sample for research purpose in future.

\section{AUTHOR CONTRIBUTIONS}

MP, GZ, JM-Q, JP, VK, DB, and DV conceived and designed the work; AK, VZ, LK, JP, EB, HN, VL, GZ, VK, and MP contributed to data acquisition; AK performed data analysis and interpretation; $\mathrm{AK}$ and MP drafted the manuscript after its revision for important intellectual context by all authors; MP and AK finalized the article. All authors have read and approved the final manuscript and agreed to be accountable for all aspects of the work.

\section{FUNDING}

Grant support: CZ.1.07/2.3.00/30.0041, LO1304, IGA_ PU_LF_2015_020, 2016_009, National Strategic Reference

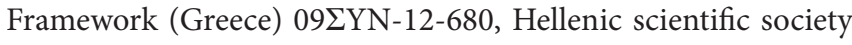
for rare diseases and orphan drugs.

\section{SUPPLEMENTARY MATERIAL}

The Supplementary Material for this article can be found online at http://journal.frontiersin.org/article/10.3389/fimmu.2016.00274 


\section{REFERENCES}

1. Raghu G, Collard HR, Egan JJ, Martinez FJ, Behr J, Brown KK, et al. An official ATS/ERS/JRS/ALAT statement: idiopathic pulmonary fibrosis: evidence-based guidelines for diagnosis and management. Am J Respir Crit Care Med (2011) 183:788-824. doi:10.1164/rccm.2009-040GL

2. Mushiroda T, Wattanapokayakit S, Takahashi A, Nukiwa T, Kudoh S, Ogura T, et al. A genome-wide association study identifies an association of a common variant in TERT with susceptibility to idiopathic pulmonary fibrosis. J Med Genet (2008) 45:654-6. doi:10.1136/jmg.2008.057356

3. Fingerlin TE, Murphy E, Zhang W, Peljto AL, Brown KK, Steele MP, et al. Genome-wide association study identifies multiple susceptibility loci for pulmonary fibrosis. Nat Genet (2013) 45:613-20. doi:10.1038/ng.2609

4. Hutyrova B, Pantelidis P, Drabek J, Zurkova M, Kolek V, Lenhart K, et al. Interleukin-1 gene cluster polymorphisms in sarcoidosis and idiopathic pulmonary fibrosis. Am J Respir Crit Care Med (2002) 165:148-51. doi:10.1164/ ajrccm.165.2.2106004

5. Ahn MH, Park BL, Lee SH, Park SW, Park JS, Kim DJ, et al. A promoter SNP rs4073T $>A$ in the common allele of the interleukin 8 gene is associated with the development of idiopathic pulmonary fibrosis via the IL-8 protein enhancing mode. Respir Res (2011) 12:73. doi:10.1186/1465-9921-12-73

6. O’Dwyer DN, Armstrong ME, Trujillo G, Cooke G, Keane MP, Fallon PG, et al. The toll-like receptor $3 \mathrm{~L} 412 \mathrm{~F}$ polymorphism and disease progression in idiopathic pulmonary fibrosis. Am J Respir Crit Care Med (2013) 188:1442-50. doi:10.1164/rccm.201304-0760OC

7. Vasakova M, Sterclova M, Matej R, Olejar T, Kolesar L, Skibova J, et al. IL-4 polymorphisms, HRCT score and lung tissue markers in idiopathic pulmonary fibrosis. Hum Immunol (2013) 74:1346-51. doi:10.1016/j. humimm.2013.07.011

8. Zhang HP, Zou J, Xie P, Gao F, Mu HJ. Association of HLA and cytokine gene polymorphisms with idiopathic pulmonary fibrosis. Kaohsiung J Med Sci (2015) 31:613-20. doi:10.1016/j.kjms.2015.10.007

9. Seibold MA, Wise AL, Speer MC, Steele MP, Brown KK, Loyd JE, et al. A common MUC5B promoter polymorphism and pulmonary fibrosis. $N$ Engl J Med (2011) 364:1503-12. doi:10.1056/NEJMoa1013660

10. Kishore A, Zissel G, Zizkova V, Mueller-Quernheim J, Petrek M. Association of mucin (MUC2, MUC5B) gene variants with idiopathic pulmonary fibrosis (IPF) in a German population: a pilot study using MassARRAY technology. Tissue Antigens (2015) 85:340. doi:10.1111/tan.12557

11. Korthagen NM, van Moorsel CH, Barlo NP, Kazemier KM, Ruven HJ, Grutters JC. Association between variations in cell cycle genes and idiopathic pulmonary fibrosis. PLoS One (2012) 7:e30442. doi:10.1371/journal. pone.0030442

12. Petrek M, Kishore A, Zizkova V. Genetic association study for idiopathic pulmonary fibrosis in a Czech population: results from a pilot study using massarray technology. Am J Respir Crit Care Med (2015) 191:A4382-A. doi:10.1164/ajrccm-conference.2015.191.1_MeetingAbstracts.A4382

13. Uh ST, Kim TH, Shim EY, Jang AS, Park SW, Park JS, et al. Angiotensinconverting enzyme (ACE) gene polymorphisms are associated with idiopathic pulmonary fibrosis. Lung (2013) 191:345-51. doi:10.1007/s00408-013-9469-1

14. Huang Y, Ma SF, Vij R, Oldham JM, Herazo-Maya J, Broderick SM, et al. A functional genomic model for predicting prognosis in idiopathic pulmonary fibrosis. BMC Pulm Med (2015) 15:147. doi:10.1186/s12890-015-0142-8

15. Kishore A, Zizkova V, Kocourkova L, Petrek M. A dataset of 26 candidate gene and pro-inflammatory cytokine variants for association studies in idiopathic pulmonary fibrosis: frequency distribution in normal Czech population. Front Immunol (2015) 6:476. doi:10.3389/fimmu.2015.00476

16. Little J, Higgins JP, Ioannidis JP, Moher D, Gagnon F, von Elm E, et al. Strengthening the reporting of genetic association studies (STREGA): an extension of the STROBE statement. Eur JEpidemiol (2009) 24:37-55. doi:10.1007/s10654-008-9302-y

17. Heath SC, Gut IG, Brennan P, McKay JD, Bencko V, Fabianova E, et al. Investigation of the fine structure of European populations with applications to disease association studies. Eur J Hum Genet (2008) 16:1413-29. doi:10.1038/ ejhg.2008.210

18. Lundmark PE, Liljedahl U, Boomsma DI, Mannila H, Martin NG, Palotie A, et al. Evaluation of HapMap data in six populations of European descent. Eur J Hum Genet (2008) 16:1142-50. doi:10.1038/ejhg.2008.77

19. Sanchez-Mazas A, Vidan-Jeras B, Nunes JM, Fischer G, Little AM, Bekmane U, et al. Strategies to work with HLA data in human populations for histocompatibility, clinical transplantation, epidemiology and population genetics: HLA-NET methodological recommendations. Int J Immunogenet (2012) 39:459-72. doi:10.1111/j.1744-313X.2012.01113.x

20. Kubistova Z, Mrazek F, Tudos Z, Kriegova E, Ambruzova Z, Mytilineos J, et al. Distribution of 22cytokinegenepolymorphismsinthehealthyCzechpopulation. Int J Immunogenet (2006) 33:261-7. doi:10.1111/j.1744-313X.2006.00609.x

21. American Thoracic Society. Idiopathic pulmonary fibrosis: diagnosis and treatment. International consensus statement. American Thoracic Society (ATS), and the European Respiratory Society (ERS). Am J Respir Crit Care Med (2000) 161:646-64. doi:10.1164/ajrccm.161.2.ats3-00

22. American Thoracic Society, European Respiratory Society. American Thoracic Society/European Respiratory Society International Multidisciplinary Consensus Classification of the Idiopathic Interstitial Pneumonias. This joint statement of the American Thoracic Society (ATS), and the European Respiratory Society (ERS) was adopted by the ATS board of directors, June 2001 and by the ERS Executive Committee, June 2001. Am J Respir Crit Care Med (2002) 165:277-304. doi:10.1164/ajrccm.165.2.ats01

23. Miller SA, Dykes DD, Polesky HF. A simple salting out procedure for extracting DNA from human nucleated cells. Nucleic Acids Res (1988) 16:1215. doi:10.1093/nar/16.3.1215

24. Yang H, Robinson PN, Wang K. Phenolyzer: phenotype-based prioritization of candidate genes for human diseases. Nat Methods (2015) 12:841-3. doi:10.1038/nmeth.3484

25. Seibold MA, Smith RW, Urbanek C, Groshong SD, Cosgrove GP, Brown KK, et al. The idiopathic pulmonary fibrosis honeycomb cyst contains a mucocilary pseudostratified epithelium. PLoS One (2013) 8:e58658. doi:10.1371/ journal.pone. 0058658

26. van der Vis JJ, Snetselaar R, Kazemier KM, Ten Klooster L, Grutters JC, van Moorsel CH. Effect of Muc5b promoter polymorphism on disease predisposition and survival in idiopathic interstitial pneumonias. Respirology (2016) 21(4):712-7. doi:10.1111/resp.12728

27. Yang IV, Fingerlin TE, Evans CM, Schwarz MI, Schwartz DA. MUC5B and idiopathic pulmonary fibrosis. Ann Am Thorac Soc (2015) 12(Suppl 2):S193-9. doi:10.1513/AnnalsATS.201503-110AW

28. Uhal BD, Kim JK, Li X, Molina-Molina M. Angiotensin-TGF-beta 1 crosstalk in human idiopathic pulmonary fibrosis: autocrine mechanisms in myofibroblasts and macrophages. Curr Pharm Des (2007) 13:1247-56. doi:10.2174/138161207780618885

29. Li X, Molina-Molina M, Abdul-Hafez A, Uhal V, Xaubet A, Uhal BD. Angiotensin converting enzyme-2 is protective but downregulated in human and experimental lung fibrosis. Am J Physiol Lung Cell Mol Physiol (2008) 295:L178-85. doi:10.1152/ajplung.00009.2008

30. Alder JK, Chen JJ, Lancaster L, Danoff S, Su SC, Cogan JD, et al. Short telomeres are a risk factor for idiopathic pulmonary fibrosis. Proc Natl Acad Sci U S A (2008) 105:13051-6. doi:10.1073/pnas.0804280105

31. Wei R, Li C, Zhang M, Jones-Hall YL, Myers JL, Noth I, et al. Association between MUC5B and TERT polymorphisms and different interstitial lung disease phenotypes. Transl Res (2014) 163:494-502. doi:10.1016/j. trsl.2013.12.006

32. Hutchinson J, Fogarty A, Hubbard R, McKeever T. Global incidence and mortality of idiopathic pulmonary fibrosis: a systematic review. Eur Respir J (2015) 46:795-806. doi:10.1183/09031936.00185114

33. Kishore A, Borucka J, Petrkova J, Petrek M. Novel insights into miRNA in lung and heart inflammatory diseases. Mediators Inflamm (2014) 2014:259131. doi:10.1155/2014/259131

34. Rajasekaran S, Rajaguru P, Sudhakar Gandhi PS. MicroRNAs as potential targets for progressive pulmonary fibrosis. Front Pharmacol (2015) 6:254 doi:10.3389/fphar.2015.00254

Conflict of Interest Statement: The authors declare that the research was conducted in the absence of any commercial or financial relationships that could be construed as a potential conflict of interest.

Copyright (C) 2016 Kishore, Žižková, Kocourková, Petrkova, Bouros, Nunes, Loštáková, Müller-Quernheim, Zissel, Kolek, Bouros, Valeyre and Petrek. This is an open-access article distributed under the terms of the Creative Commons Attribution License (CC $B Y)$. The use, distribution or reproduction in other forums is permitted, provided the original author(s) or licensor are credited and that the original publication in this journal is cited, in accordance with accepted academic practice. No use, distribution or reproduction is permitted which does not comply with these terms. 